\title{
Otakus: principios narrativos y perceptivos de la japonaimación ${ }^{1}$
}

\section{Otakus: Narrative and Perceptual Guidelines of Japanimation}

\section{Luis Perillán Torres}

Universidad de Chile

luis_perillan@hotmail.com

\begin{abstract}
Resumen
El fenómeno otaku, referido a comunidades de adolescentes y adultos que gustan de la videoanimación japonesa y sus productos asociados, tiene cada vez mayor notoriedad. El texto pretende describir las características de este grupo social en Chile
\end{abstract}

Palabras clave: Otaku, japoanimación, semiótica visual.

\begin{abstract}
The 'Otaku', teen communities of japanese comics and animation consumers, as well as all asociated merchandising, have become a notorious social phenomenon this days. This paper aims to describe the caractheristics of this social group as it is presented in Chile.
\end{abstract}

Keywords: Otaku, japanimation, visual semiotic.

\section{Introducción}

A partir de la década de los noventa ha aparecido en Chile un grupo, o movimiento, de jóvenes autodenominados otakus, los cuales serían sujetos aficionados o fanáticos de la videoanimación japonesa (un compendio de dibujos animados, cómic, música y videojuegos de origen japonés) los cuales se reúnen en torno al consumo de estos productos, y se relacionan entre sí para la circulación de estos, la organización de actividades o simplemente para conocer personas con los mismos gustos. Estos otakus, aunque silenciosamente e ignorados por la gran mayoría del país, han desarrollado numerosas actividades que denotan que no se trata de un simple grupo marginal de freaks con gustos extraños, ya que han organizado en los últimos años mas de una docena de

1 Fondecyt No 1061166. 
actividades multitudinarias, además de una media docena de ciclos de animación regulares solo en Santiago, sin contar que durante varios años una de las paginas web chilenas más visitada fue un portal de anime mantenido por otakus para la difusión del anime en Chile. En el presente texto se tratará de profundizar en las particularidades de este grupo, la forma que tienen de relacionarse, cómo comprenden ellos mismos su situación, su visión del mundo adulto (independientemente de que gran parte de este grupo este formado por adultos) y principalmente como ellos constituyen una identidad y cómo ésta les permite enfrentar la realidad que les rodea. Un punto que es importante aclarar es la complejidad de lo que entendemos como 'fenómeno de los otaku'. Desde nuestra perspectiva se pueden distinguir una serie de elementos que se relacionan en la conformación de los otakus: primero que nada podemos mencionar una historia, la cual se origina en los años setenta con la proliferación de las series de dibujos animados japoneses en Chile (Candy, Mazinger $Z$ o Marco, entre otras) continuadas por lo más recientes éxitos televisivos (Sailor Moon, Dragon Ball Z, Caballeros del Zodiaco, Pokemon, Samurai X, entre otros); existen relaciones internas entre grupos que son precisas de describir y explicar; existe una relación con el entorno particular; existen las relaciones con los objetos de consumo (videoanimación) las cuales no se reducen al simple consumo mercantil de bienes; existe también una relación con la tecnología; existe una identidad en permanente construcción, la cual les permite a los otakus reconocerse entre sí; y finalmente una serie de valores y principios que se manifiestan en este grupo. Por la extensión de lo anteriormente descrito solo se presentará una introducción a los hallazgos obtenidos en el estudio de este fenómeno que, aunque bastante antiguo, recién en la actualidad ha concitado un interés en la comunidad científica y obtenido notoriedad en los medios de comunicación nacionales.

\section{Comunidades juveniles}

En el mundo juvenil las diversas estéticas se recombinan incesantemente en una vorágine dentro de la cual se vuelven difusas las distinciones que separan a cada sujeto de los demás. Cada símbolo se homologa a los otros para solo transformarse en un signo de ubicación dentro de una red, es decir un anuncio de 'yo estoy aquí' o 'yo soy de allí, en el cual la diferencia de locación no es más importante que el distintivo que lo señala. Es lo que se puede denominar a grandes rasgos integración social en un sistema capitalista de consumo, en el cual la identidad de cada sujeto se puede transar según ciertas leyes de mercado, el cual regula el flujo de los símbolos que denotan distinciones de origen, ubicuidad o bien de capacidad de adquisición.

Sin embargo la postura que explica la integración en el consumo, sostenida por autores como Garcia-Canclini (1990), no da habida cuenta de ciertos esquemas que violentan los patrones mercantiles, socavan sus estructuras y cuestionan sus principios, los llamados movimientos underground desarrollan otros modelos de integración en los cuales el escenario en que se construye la identidad es el interior del propio grupo, pese a lo cual pueden ser reconocidos desde fuera de éste por ciertos símbolos, difíciles de interpretar por quien no pertenezca al grupo, los 
cuales denotan una cierta anormalidad (en el sentido social del término). Sin embargo, en gran medida estos sujetos permanecen invisibles para el resto de la sociedad. Cuando hablamos de movimientos underground no hay que pensar solo en movimientos como el punk o el skinhead, los cuales manifiestan su simbolismo como respuesta a una sociedad que no les satisface, sino que también hay que pensar en movimientos más invisibles centrados en el consumo y el culto al saber, en este caso el grupo al que nos referiremos son los otakus, también conocidos como los fanáticos de la animación japonesa (anime, según la denominación por la que es conocida en el mundo occidental) o para ser más exactos: fanáticos de la videoanimacion japonesa.

\section{Videoanimación}

El concepto de videoanimación es demasiado a menudo confundido con el de dibujos animados, los cuales, aunque se encuentran englobados dentro del concepto de videoanimación, no agotan la amplitud del espacio que este representa. Para definir lo que entenderemos por videoanimación hay que remitir al trabajo de Rafael del Villar (2005), quien ha conceptualizado la videoanimación como un fenómeno multisoporte, el cual en el caso de la videoanimación japonesa engloba tanto las series de dibujos animados como a las revistas de cómics (conocidas como manga), los diversos videojuegos existentes, juegos de cartas (trading cards), páginas web, revistas especializadas (de diversa procedencia), música y videoclips. Es importante constatar que esta relación multisoporte se constituye no por medio del consumo de los sujetos sino, por el contrario, por una discontinuidad narrativa o de referencialidad, esto es: cada uno de los elementos contribuye con una parte de la información necesaria para entender el todo. Por ejemplo: la serie de TV muestra escenas que no aparecen en el cómic, mientras que este explica algunas partes que no se entienden de la serie o que no se animaron, los videojuegos permiten al sujeto participar de la acción y en ocasiones incluyen información adicional, las revistas hacen recopilaciones de información y orientan al sujeto consumidor, los juegos de cartas permiten al sujeto interactuar con otros aficionados, las paginas web cumplen tanto la función de informar como permitir la interacción de los aficionados por medio de foros. Todo lo anterior se aprecia con facilidad en el fenómeno Pokemon, el cual nace como un videojuego pero pronto se expande a todas las demás áreas constituyendo una de las redes multisoporte más completas del mercado, a las cuales hay que sumarles algunas distinciones como los filmes, merchandising o los doujinshis (comic hechos por aficionados que corrigen, complementan o distorsionan la historia original).

\section{Japoanimación}

El desarrollo de la animación japonesa se produce a partir de los años setenta con el progresivo desarrollo de series de animación para público infantil en el Japón, las cuales tiene una estrecha relación con los manga japoneses, por lo cual heredará de éstos los principios estéticos que la particularizan. 
En Japón, como en el resto del mundo, es común que los dibujos animados se basen en las series de cómics (se puede citar el caso de Dragon Ball, Sailor Moon o Los Caballeros del Zodiaco, o los casos de Spirou, Superman o Spiderman en occidente) por lo cual la relación estética que se mantiene entre estos es muy fuerte, pese a las innegables trasformaciones que se experimentan en el traspaso de la forma estática del papel al movimiento de la pantalla, tal como lo afirma Danielle Barbieri (1991: 223-241).

Las principales características que hereda el anime del manga son tres: la temporalidad en el relato; el predominio de la imagen sobre el texto; y el lenguaje icónico. Estas tres características se pueden entender por separado, sin embargo es necesario verlas como un todo para apreciar la especificidad del lenguaje del anime y del manga.

La temporalidad del relato del manga y del anime tiene mucha relación con la estética tradicional japonesa del teatro kabuki, la cual busca crear una atmósfera narrativa extraña en la que se imbuye al espectador en una especie de complicidad, lo cual funciona principalmente mediante el ritmo narrativo pausado (Berndt, 1996: 83), que se verá reflejado en la narrativa del manga y el anime en los que las acciones son narradas durante mucho tiempo de 'lectura', mientras que el tiempo narrado es en comparación muy breve. Esta ambivalencia es producto de que las acciones en el manga pueden ser desarrolladas durante varias viñetas, de manera tal que se pueden graficar numerosos aspectos de una misma acción (como señala Berndt: "cada acción suele ocupar mas de dos viñetas; a igualdad del fondo, aparece la secuencia de acción como una serie de imágenes, aprovechando además el principio del montaje para que la mirada del lector se vea obligada a fundirse con las figuras" [1996: 48]), lo cual se traduce, en el caso del anime, en escenas de enorme duración pero en las cuales transcurre muy poco tiempo narrado; por ejemplo, escenas en las cuales los personajes se mantienen 10 o 20 segundos en el aire tras un salto, acción que no debería tomar más de un segundo. Esta especie de "cámara lenta" (aunque en estricto rigor no se percibe de esa manera, ya que la secuencia tiene la velocidad que requiere la trascendencia de la acción) permite dotar de un mayor dinamismo la lectura, que suele fluir con facilidad de una escena a otra, incluyendo la lectura paralela de varias viñetas, y permite el desarrollo de la segunda característica del manga y el anime, el predominio de la imagen sobre el texto.

Cuando hablamos del predominio de la imagen sobre el texto no hay que pensar en un lenguaje similar al de la pintura o la ilustración, en las cuales todo el contenido se debe expresar sin la participación de texto, solo con la imagen presente, sino todo lo contrario, la imagen en el manga y el anime tiende a expresar muy poco, de tal manera que la lectura de una imagen es más rápida que en el caso del comic o dibujo animado occidental, pese a lo cual la mayor parte del contenido se expresa, a diferencia del comic occidental, de manera visual (en oposición a la maneta textual de transmisión de contenidos del comic occidental). La explicación a esto está, en parte, dada por la temporalidad del manga y el anime, y el lenguaje icónico de éste, ya que la acción se divide en más viñetas (una sola viñeta no explica una acción) y se recurre a otros lenguajes, fuera del lenguaje textual, para expresar las acciones. Sin embargo, de por si la esencia del manga se encuentra en la narración visual, tratando de prescindir en la mayor medida posible de textos que expliquen lo que está ocurriendo, de los globos de pensamiento y también de las 
didascalias (textos explicativos que sobreentienden la existencia de un narrador). Lo ideal del manga y del anime es que la acción se entienda sólo en forma visual, incluso las líneas de movimiento se ven reducidas al reemplazarlas por el movimiento que denotan las relaciones entre las viñetas: "Narran sin palabras. El texto va disociado de la imagen de manera que esta y aquel se complementan" (Berndt, 1996: 48).

El lenguaje icónico termina por complementar el carácter visual del manga y del comic, el cual permite, según J. Berndt (siguiendo a Yoshitake Ôshiro), que la comunicación no se desarrolle en términos verbales si no que "por vía de múltiples alusiones y lenguaje gestual, casi como una especie de 'transmisión del pensamiento'” (1996: 48), lo cual implicaría el manejo de un código, el cual por lo demás es fácilmente asimilable mediante el lenguaje visual del manga. Por lo tanto, se constituye un tercer lenguaje complementario al visual y al textual que permite complejizar, en cuanto a contenido, sin por ello dificultar la comprensión del mismo. Ejemplos clásicos de este lenguaje son la gota que cae de la cabeza de los personajes, normalmente cuando escuchan alguna estupidez, o la vena exaltada cuando un personaje está furioso, tal como exponen Lechuga et al. en Semiótica de la Japoanimación (1998: 83).

Dentro del lenguaje iconográfico se podría eventualmente entender también las deformaciones estéticas del cuerpo en el manga y el anime ('el cuerpo como signo' según Berndt), las cuales tienen por primera función simbolizar ciertos rasgos para una mayor comprensión de parte del espectador. De esta manera, los ojos grandes aparecen como un símbolo no realista de los sentimientos, por lo que serán normalmente los personajes principales los que posean grandes ojos (en especial los personajes femeninos o los niños, los cuales son representados con mayor emotividad en la sociedad japonesa); también las formas exageradas se utilizaran para representar la belleza de una mujer (desproporcionados pechos, largas piernas y enorme cabello, lo cual está muy presente en el manga erótico o hentai) o el poder de un combatiente (principalmente una enorme masa de músculos o un enorme tamaño, muchas veces acompañado de toscos rostros). De esta manera se facilita la comprensión de las características del personaje mediante la apariencia física, la cual en si misma pasa a ser un código narrativo.

\section{Conclusión}

Todo lo anteriormente descrito tiene por consecuencia que la japoanimación facilita la comprensión, gracias a la preferencia hacia el lenguaje audiovisual, de la narratividad del manga anime, lo que permite que, por un lado, sea de fácil comprensión para los niños, que tienen una mejor comprensión del lenguaje visual que del textual (lo cual es avalado por los resultados del estudio "la televisión y los niños en Chile, percepciones desde la audiencia infantil", en el cual se muestra que los dibujos animados son los programas de más fácil comprensión para el público infantil, con un 47,9\% de las preferencias [Medel, 1999]) y, por otro lado, una mayor facilidad para la comprensión transcultural ya que los contenidos culturales particulares son mediatizados por este lenguaje visual, que es de fácil adquisición por parte del espectador, lo que permite al 
sujeto incorporarlo a sus códigos culturales. Esto es fundamental para entender la masificación de la japoanimación en el mundo occidental (y con esto el surgimiento de la cultura otaku en la mayor parte del mundo). Por lo tanto, la iconografía de la japoanimación permite que un sujeto entienda el mensaje como si fuera con sus propios contenidos culturales. Lo anterior es afirmado también por las teorías sobre la percepción cognitiva que sostienen que los textos son captados desde los "mundos posibles semántico-pulsionales" (Del Villar, 2002), es decir: toda percepción es ante todo una interpretación de la realidad, la cual no obedece a una estructura lógica o lineal, no hay una sola manera de entender el texto, en este caso audiovisual, sino que cada uno lo entiende a partir de la experiencia adquirida.

(... ) la percepción es un fenómeno cognitivo que no obedece a una estructura lógica como creía el cognitivismo (que lo pensaba a semejanza de la forma de funcionamiento del computador con una sintaxis especifica), sino que enactivos (Varela, 1989, 1996, 1992), donde el sujeto reconstruye su percepción no por la lógica, ni por lo que percibe en lo real, sino que $20 \%$ de lo percibible se capta por los sensores cerebrales, y el $80 \%$ es reconstruida por los archivos mentales, la experiencia pasada y las conexiones entre variables (Del Villar, 2005)

La japoanimación caló profundamente en el imaginario infantil de los años setenta (con la primera oleada de anime en Latinoamérica) de la misma manera que ya lo había hecho en Japón en la década de los sesenta, permitiendo de esta manera que las generaciones infantiles al crecer y madurar conservasen la comprensión del lenguaje de anime y ya en su etapa adulta pudieran reintroducirse en el consumo de dibujos animados japoneses, los cuales ya habían cambiado mucho desde los años setenta y presentaban temáticas adultas y hasta eróticas, con nuevos formatos y una mayor diversidad temática, lo que obedece también a las transformaciones del público consumidor japonés que también había madurado.

De esta manera surgen los primeros grupos otakus en Chile a principios de los noventa, aproximadamente quince años después de la primera llegada de anime al país, de la misma manera que habían surgido en Japón a principios de los ochenta, unos quince años después de la aparición de las primeras series de animación japonesa (Tetsuwan Atomu, 1965, también conocida como Astro Boy): un grupo centrado en el consumo, colección y clasificación de anime y de información varia sobre esta, grupo que, como lo describe Etienne Barral, se centra en la negación de la participación del orden social, prefiriendo el refugio evasivo en el anime o en otras actividades de consumo: "inadaptados sociales que se refugian en un mundo virtual" (Barral, 1999: 22; traducción propia).

Sin duda que son estas características narrativas de la videoanimación japonesa las que permitieron que un fenómeno tan propio de Japón, como son los otaku, se transformara en un fenómeno social multicultural, el que se encuentra difuminado hoy por gran parte del mundo occidental y del oriental. 


\section{Bibliografía de Referencia}

Barbieri, D. (1993) Los lenguajes del cómic. Barcelona: Paidos.

Berndt, J. (1996) El fenómeno del manga. Barcelona: Martines Roca.

Barral, É. (1999) Otaku: les enfants du virtuel. Paris: Denoël.

Del Villar, R. (2002) "Multiculturalismo e integración: hacia una imagen corporativa global". Santiago de Chile: II Encuentro de Facultades de Comunicación Social del Cono Sur.

------ (2005) “Informe FONDECYT N¹030561: Videoanimación y construcción de identidades”. Santiago de Chile.

García Canclini, N. (1990) Culturas híbridas: estrategias para entrar y salir de la modernidad. México: Grijalbo.

Lechuga, L., Letelier, L., Poblete, P. y Labrin, J. (1998) Semiótica de la Japoanimación. Tesis de Comunicación Social. Universidad de Chile.

Medel, I. (1999) Japoanimación: una travesía semiológica de la película Sailor Moon. Tesis de Comunicación Social. Universidad de Chile. 